\title{
SELF-INSTRUSCTION SEBAGAI TEKNIK ALTERNATIF MENINGKATKAN KEPERCAYAAN DIRI (OVERT-COVERT) SISWA SMP
}

\author{
ROMIA HARI SUSANTI \\ Universitas Kanjuruhan Malang \\ romi@unikama.ac.id
}

\begin{abstract}
Poor self-concept in adolescents, one of which can be seen from the lack of self-confidence. The student who has confidence will be certain in their abilities and have realistic expectations, and when expectations do not materialize, they still think positively and can receive it. Unrealistic expectations can be reduced by using techniques that can direct students to control negative cognitive behaviors and thoughts that cause low student confidence (overt-covert). Wilcoxon test analysis results show that sig. (2-tailed) $0.042<0.05$ which can be interpreted as a technique of self-instruction can increase the confidence of students of SMP Muhammadiyah 4 Singosari, with a significant level of $5 \%$. The use of self-instruction techniques as an alternative technique to increase student confidence starts from rational procedures, self-guidance, overt external guidance, overt self-guidance, faded overt selfguidance, covert self-guidance, and homework.
\end{abstract}

\section{ABSTRAK}

Buruknya konsep diri pada remaja salah satunya dapat dilihat dari adanya ketidakpercayaan diri. Siswa yang percaya diri yakin atas kemampuan diri serta memiliki pengharapan yang realistis.Tujuan penelitian eksperimen ini adalah mengurangi pengharapan tidak realistis dengan menggunakan teknik instruksi diri yang dapat mengarahkan siswa untuk mengontrol perilaku dan pemikiran-pemikiran negatif yang menimbulkan rendahnya rasa percaya diri (overt-covert). Hasil analisis uji wilcoxon menunjukkan bahwa sig. (2-tailed) 0,042<0,05 yang dapat diartikan teknik self instruction dapat meningkatkan kepercayaan diri siswa SMP Muhammadiyah 4 Singosari dengan taraf signifikan 5\%. Penggunaan teknik self instruction sebagai alternatif teknik untuk meningkatkan kepercayaan diri siswa dimulai dari prosedur rasional, bimbingan diri sendiri, overt eksternal guidance, overt self guidance, faded overt self guidance, covert self guidance, dan homework.

Cara mengutip: Susanti, Romia (2020) Self Instruction Sebagai Teknik Alternatif Meningkatkan Kepercayaan Diri (Overt-Covert) Siswa SMP. Nusantara of Research : Jurnal Hasil-Hasil Penelitian Universitas Nusantara PGRI Kediri (e-Journal), 7(1), 1-8. https://doi.org/10.29407/nor.v7i1.14029

\section{PENDAHULUAN}

Remaja yang memiliki kepercayaan diri rendah dapat diartikan remaja tersebut adalah orang yang belum memiliki kepuasan akan kondisi dirinya. Ketidak percayaan pada remaja bisa dilihat dari adany a perilaku menarik diri, tidak ingin terlibat dalam kegiatan sosial atau aktivitas dengan teman-teman sebaya, memperlihatkan gerakgerik yang canggung ketika berhadapan dengan orang lain, memiliki rasa takut untuk tampil, pesimis dan kurang adanya motivasi untuk melakukan suatu usaha, mudah tersinggung, sulit mengambil keputusan untuk hal-hal kecil dan selalu peduli dengan 
komentar orang lain, (Gael,1997). Hasil survey awal peneliti pada bulan Mei 2019 di salah satu sekolah swasta Malang menggambarkan data adanya siswa yang menunjukkan kondisi rendahnya kepercayaan diri di dalam kelas, yaitu tidak berani mengungkapkan pendapat, tidak berani maju ke depan kelas untuk menyampaikan materi yang telah diajarkan oleh guru dan tidak berani bertanya ketika ada materi yang kurang dipahami. Hasil observasi juga menunjukkan masalah kurangnya rasa percaya diri siswa sekolah menengah pertama adalah kesulitan berbicara didepan kelas, dan juga dalam hal mengemukakan pendapat dikelas, sehingga diperlukan adanya teknik yang bisa membantu siswa mengembangkan rasa percaya dirinya.

Menurut De Angelis (2005) percaya diri merupakan salah satu aspek kepribadian yang sangat penting dalam kehidupan manusia. Orang yang percaya diri memiliki keyakinan atas kemampuan mereka sendiri serta memiliki pengharapan yang realistis, bahkan ketika harapan mereka tidak terwujud, mereka tetap berfikiran positif dan dapat menerimanya. Tindakan individu yang percaya diri akan meng hasilkan kesuksesan. Individu yang memiliki rasa percaya diri akan menghasilkan pola siklus yang terus berlangsung tergantung dengan besar kecilnya rasa percaya diri dalam hidup individu, (Gael,1997). Individu yang tidak memiliki rasa percaya diri atau rendah diri, maka hanya ada dua kemungkinan yang terjadi dari siklus tersebut yaitu tidak ada tindakan yang dilakukan oleh individu atau tindakan tidak optimal. Sebaliknya apabila seseorang merasa percaya diri, maka apapun tindakan yang dilakukan oleh setiap individu dapat dicapai secara optimal atau maksimal.

Hurlock (2006) untuk mencapai kematangan emosi, remaja harus belajar memperoleh gambaran tentang situasi-situasi yang dapat menimbulkan reaksi emosional. Reaksi emosi dan kognitif yang positif bisa dibangun menggunakan teknik-teknik tertentu dalam bimbingan dan konseling. Teknik self instruction dari pendekatan Cognitive Behavioural Therapy (CBT) diharapkan mampu meningkatkan rasa percaya diri yang dimiliki oleh remaja karena inti dari teknik iniadalah merestrukturasi sistem kognisi konseli, namun terpusat pada perubahan pola verbalisasi overt dan covert (Cormier, 2009). Meichenbaum (2008) mengungkapkan bahwa teknik self instruction adalah cara untuk individu mengajarkan pada diri mereka sendiri bagaimana cara menangani situasi yang sulit bagi diri mereka sendiri. Jadi teknik self instruction akan membantu siswa atau individu dalam mengontrol perilaku dan pemikiran-pemikiran negatif yang dapat menyebabkan kurangnya percaya diri.

Self instruction merupakan teknik yang membentuk ulang pola-pola kognitif, asumsiasumsi, keyakinan-keyakinan, dan distorsi pikiran, yang merusak dan menyalahkan diri sendiri. Praktiknya konselor dapat menguji ulang keyakinan siswa terhadap diri mereka dengan menggunakan berbagai teknik persuasi verbal dan aktivitas yang diberikan secara berulang-ulang sampai pada akhirnya siswa dapat melakukannya untuk diri sendiri (Cormier, 2009). Teknik self instruction Cognitive Behavioural Therapy (CBT) mengajarkan individu bagaimana menangani situasi yang sulit bagi diri mereka.

Self instruction memberikan keterampilan bantu diri agar siswa mampu mengatasi masalah yang mengganggu keyakinannya dengan cara mengubah pikiran negatif menjadi pikiran positif yang selanjutnya diucapkan pada diri sendiri dengan suara lantang, samar atau 
hanya dalam hati sehingga membantu siswa percaya diri (Cormier,2009). Kepercayaan diri pada remaja merupakan salah satu life skill yang perlu dimiliki untuk meraih kesuksesan.Kepercayaan diri membuat siswa dapat menyalurkan segala sesuatu yang diketahui dan dikerjakan secara positif. Kepercayaan diri juga merupakan sikap positif individu yang membuat dirinya mampu mengembangkan penilaian positif terhadap diri sendiri maupun terhadap lingkungan.

Menurut Fatimah (20016) agar bisa menumbuhkan rasa percaya diri secara proporsional, individu harus memulai dari diri sendiri, salah satunya dengan cara berfikiran positif. Pikiran positif adalah melawan setiap asumsi, prasangka atau persepsi negatif yang muncul di benak, dan tidak membiarkan pikiran negatif berlarut-larut. Kondisi ini bisa diupayakan melalui penggunaan teknik yang mengarahkan individu untuk memelihara pikiran positifnya melalui proses kontrol diri. Alternatif teknik yang bisa diberikan adalah self instruction, karena inti dari teknik ini adalah membantu siswa merestrukturisasi sistem kognisi melalui kontrol perilaku dan pikiran negatif (Cormier,2009).

\section{METODE}

Rancangan penelitian yang digunakan adalah pre eksperimen desain one group pretest posttest design. Teknik pengambilan sampel penelitian yang digunakan adalah purposive sampling dengan ciri yang sudah ditentukan yaitu siswa yang memilki kepercayaan diri rendah di SMP Muhammadiyah 4 Singosari Malang. Adapun tahap pelaksanaan penelitian yang dilakukan adalah: 1)Tahap persiapan meliputi penyusunan instrument penelitian berupa skala kepercayaan diri dan pedoman eksperimen yang didalamnya meliputi prosedur operasional, self guidance, overt external guidance, overt self guidance, faded overt self guidance, covert self guidance, dan homework; 2) Validasi bahan perlakuan dan instrumen penelitian berupa skala kepercayaan diri; 3) Pemberian tes awal untuk mengukur tingkat kepercayaan diri (overtcovert) siswa sebelum diberi perlakuan (treatment); 4) Penentuan kelompok bimbingan yang didasarkan pada data: a) Hasil analisis skala kepercayaan diri dan b) Hasil observasi beberapa perilaku yang ditunjukkan siswa meliputi cenderung malu-malu ataupun canggung, tidak berani bertanya atau maju ke depan kelas saat pelajaran, rendah diri, dan cenderung menyalahkan orang lain terkait kegagalan yang dialami; 5) Pemberian treatment yaitu dengan cara menerapkan teknik self instruction sebanyak 4 kali pertemuan; 6) Pemberian tes akhir untuk mengukur perubahan tingkat kepercayaan diri (overt-covert) siswa setelah diberi perlakuan (treatment). Pengolahan data hasil pretes dan posttest dengan menggunakan analisis uji wilcoxon, dengan hipotesis teknik self instruction efektif sebagai teknik alternatif dalam meningkatkan kepercayaan diri (overt-covert) siswa SMP.

\section{HASIL}

Data hasil analisis pretest dan postest siswa dalam penelitian dapat dilihat pada grafik 1. Hasil pretest dari 36 subjek penelitian menunjukkan skor minimun tingkat kepercayaan diri adalah 46 dan skor maksimum adalah 81 dengan rerata 59,6. Sedangkan data postes menghasilkan skor minimum 71 dan maksimum 153 dengan rerata 113,02. Data ini menunjukkan beda mean antara skor pretes dan postest adalah 53,42 dan hasil uji wilcoxon menunjukkan nilai beda $(z)$ sesudah kegiatan eksperimen berupa penggunaan teknik self 
instruction adalah -2.032 dan sig.(2-tailed) adalah 0,042. Jika probabilitas >0,05, maka $\mathrm{H}_{0}$ diterima, sedangkan $\mathrm{H}_{A}$ ditolak. Sebaliknya probabilitas $<0,05$, maka $\mathrm{H}_{0}$ ditolak, sedangkan $\mathrm{H}_{\mathrm{A}}$ diterima. Analisis uji wilcoxon menunjukkan hasil bahwa sig. (2-tailed) 0,042<0,05 yang dapat diartikan teknik self instruction efektif untuk meningkatkan kepercayaan diri siswa SMP Muhammadiyah 4 Singosari dapat diterima kebenaran dalam taraf signifikan 5\%. Rasa senang dan nyaman dalam proses konseling kelompok akan mengarahkan siswa ke hal positif, sehingga melatih mereka dalam menerapkan tahapan self instruction di kehidupan sehari-hari dikarenakan dapat mengontrol perilaku negatif.

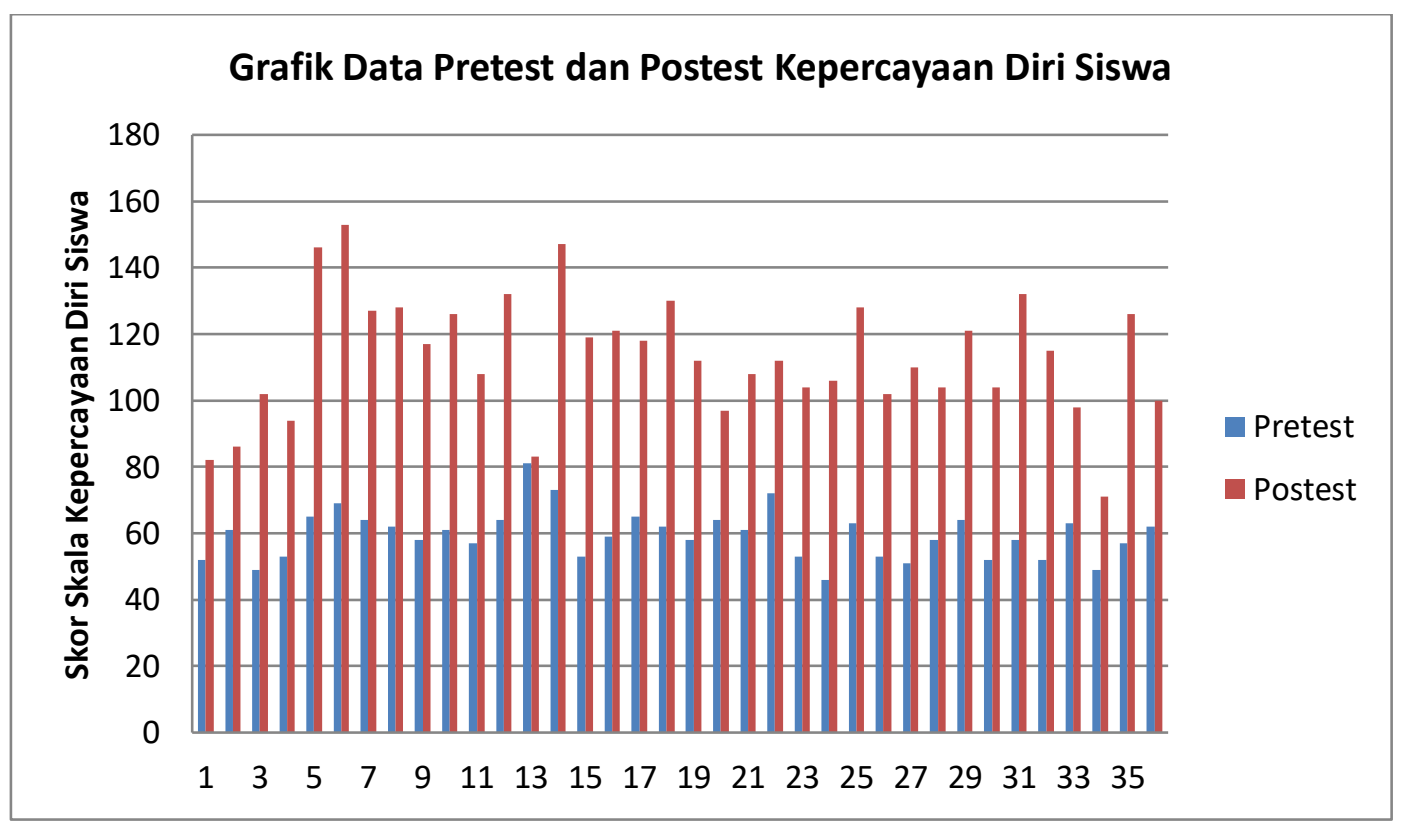

Grafik 1. Data Pretes dan Postest Skala Kepercayaan Diri Siswa SMP

Hasil pretest dari 36 subjek penelitian menunjukkan skor minimun tingkat kepercayaan diri adalah 46 dan skor maksimum adalah 81 dengan rerata 59,6. Sedangkan data postes menghasilkan skor minimum 71 dan maksimum 153 dengan rerata 113,02. Data ini menunjukkan beda mean antara skor pretes dan postest adalah 53,42 dan hasil uji wilcoxon menunjukkan nilai beda ( $\mathrm{z}$ ) sesudah kegiatan eksperimen berupa penggunaan teknik self instruction adalah -2.032 dan sig.(2-tailed) adalah 0,042. Jika probabilitas >0,05, maka $\mathrm{H}_{0}$ diterima, sedangkan $\mathrm{H}_{A}$ ditolak. Sebaliknya probabilitas $<0,05$, maka $\mathrm{H}_{0}$ ditolak, sedangkan $\mathrm{H}_{A}$ diterima. Analisis uji wilcoxon menunjukkan hasil bahwa sig. (2-tailed) $0,042<0,05$ yang dapat diartikan teknik self instruction efektif untuk meningkatkan kepercayaan diri siswa SMP Muhammadiyah 4 Singosari dapat diterima kebenaran dalam taraf signifikan $5 \%$. Rasa senang dan nyaman dalam proses konseling kelompok akan mengarahkan siswa ke hal positif, sehingga melatih mereka dalam menerapkan tahapan self instruction di kehidupan sehari-hari dikarenakan dapat mengontrol perilaku negatif.

\section{PEMBAHASAN}

Hipotesis dalam penelitian ini bisa diterima berdasarkan hasil analisis beda mean antara skor pretes dan postest adalah 53,42 dan hasil uji wilcoxon menunjukkan nilai beda $(\mathrm{z})$ sesudah kegiatan eksperimen berupa penggunaan teknik self instruction adalah -2.032 dan 
sig.(2-tailed) adalah 0,042. Hasil uji wilcoxon menunjukkan bahwa sig. (2-tailed) 0,042<0,05 yang dapat diartikan teknik self instruction efektif untuk meningkatkan kepercayaan diri siswa SMP Muhammadiyah 4 Singosari dapat diterima kebenaran dalam taraf signifikan 5\%.

Data pengukuran awal (pretest) menunjukkan bahwa 36 subjek pada penelitian teknik self instruction rata-rata memiliki tingkat kepercayaan diri yag rendah. Kondisi ini kemungkinan disebabkan karena siswa kurang percaya diri dan cenderung berdiam diri saat pembelajaran dikelas dikarenakan malu untuk bertanya kepada teman dan guru, apabila diminta untuk menyampaikan pendapat ataupun diminta tolong mengerjakan tugas ke depan kelas, siswa cenderung malu dan berdiam diri. Data pretest menunjukkan sebagian besar tingkat kepercayaan diri siswa masuk kategori rendah, sehingga peneliti memberikan treatment berupa teknik self intruction untuk mengatasi masalah-masalah yang berhubungan dengan kurangnya kepercayaan diri siswa baik overt maupun covert.

Hasil analisis penelitian ini cukup membantu dalam menjawab rumusan masalah mengenai efektifitas teknik self Intruction untuk meningkatkan kepercayaan diri (overtcovert) siswa SMP Muhammadiyah 4 Singosari. Analisis yang dilakukan adalah dengan membandingkan data sebelum (pretest) dan hasil yang diperoleh pada pengumpulan data sesudah pemberian treatment berupa teknik self intruction (posttest). Analisis penelitian menunjukkan data tingkat kepercayaan diri siswa sebelum treatment adalah rata-rata rendah. Setelah diberi treatment berupa teknik self instruction data tingkat kepercayaan diri siswa menunjukkan perubahan. Data skor skala kepercayaan diri siswa SMP Muhammadiyah 4 Singosari, lebih tinggi setelah pemberian treatment dari pada skor skala kepercayaan diri sebelum diberikan treatment dengan perubahan kategori kepercayaan dirinya menjadi kategori sedang, tinggi dan sangat tinggi.

Berdasarkan hasil postest diketahui bahwa subjek mengalami peningkatan tingkat kepercayaan diri, yang disebabkan oleh beberapa kemungkinan yaitu: 1) Proses penggunaan teknik self instruction yang meliputi overt self guidance, faded overt self guidance, covert self guidance, dan homework, memfasilitasi diri siswa yang memiliki karakter unik yaitu cenderung tidak suka diajari oleh orang dewasa untuk menjadi pribadi yang lebih percaya diri tanpa ada banyak instruksi atau perintah dari orang dewasa, 2) dalam pemberian treatment siswa lebih berani dan percaya diri untuk menyimpulkan atau berdiskusi mengenai apa yang menurut mereka sulit yang dimana akan membuat siswa lebih berfikir kreatif dan mau untuk bersaing secara sehat. 3) Siswa mampu menyesuaikan diri baik antar individu dalam kelompok maupun individu luar kelompok sehingga mereka akan terus merasa bahwa mengikuti pelajaran dikelas menjadi menarik dan banyak hal yang bisa dilakukan serta akan ada banyak informasi yang diperoleh, sehingga siswa tidak malu lagi maju kedepan kelas untuk bertanya kepada teman ataupun guru, 4) Masing-masing siswa lebih cepat memahami materi dan praktik penerapan tahapan self instruction karena siswa ikut terlibat, 5) Rasa senang, berani dan nyaman pada saat penerapan teknik self instruction membantu siswa mengontrol perilaku negatif, 6) Secara perlahan siswa akan termotivasi untuk melakukan tahapan-tahapan self instruction yang menyenangkan dikehidupan mereka sehari-hari karena teknik ini mengajarkan pada diri individu hal positif 
dan 7) Penyampaian materi dan pembelajaran self instruction melalui konseling kelompok dapat menyingkirkan rasa kurang percaya diri yang menghambat diri siswa, membuat mereka tidak berani melangkah ke hal positif untuk meningkatkan kepercayaan diri.

Dari hasil pengamatan, terjadi perubahan perilaku tingkat kepercayaan diri yang signifikan pada semua subjek penelitian. Perubahan perilaku yang tampak yaitu mulai menunjukkan sikap tidak malu untuk maju kedepan menjadi dirinya sendiri, mampu bertanya tanpa rasa takut dan malu, menunjukkan pemikiran positif dan mampu menghadapi tantangan yang ada. Misalnya, jika disuruh maju kedepan oleh guru maka tanpa raguragu untuk kedepan dan memaparkan jawabannya, apabila dalam suatu pembelajaran siswa kurang memahami maka memberanikan diri bertanya tanpa rasa takut dan malu, apabila dimintai tolong mengisi ceramah harian setelah sholat dhuha siswa dengan sergap maju tanpa ragu-ragu dan percaya diri.

Menurut Meichenbaum 2008 teknik self intruction merupakan suatu teknik modifikasi perilaku yang memiliki dua kegunaan, yaitu mengganti pemikiran negatif terhadap dirinya sendiri menjadi pemikiran positif serta dapat digunakan untuk mengarahkan perilaku. Kemudian kegiatan konseling kelompok yang terdiri dari 5-10 orang/siswa. Teknik Self intruction berfokus pada membantu konseli menjadi sadar diri untuk bisa berbicara pada dirinya sendiri. Proses terapi terdiri dari mengajarkan klien untuk membuat pernyataan diri dan melatih konseli untuk memodifikasi petunjuk yang mereka sendiri sehingga mereka dapat mengatasi lebih efektif masalah yang mereka hadapi. Bersama-sama konselor dan konseli mengintruksi perilaku yang diinginkan dalam situasi yang mensimulasikan situasi masalah konseli dalam kehidupan sehari-hari. Penekanannya adalah pada perolehan keterampilan praktis untuk mengatasi situasi bermasalah seperti perilaku impulsive dan agresif, takut mengambil tes, takut berbicara di depan umum.

Sedangkan Menurut Vigotsky (2003), tahapan terpenting dalam teknik self instruction adalah individu secara perlahan berubah dari berbicara secara keras, kemudian mulai berbicara secara lirih di dalam hatinya. Vigotsky (2003) menegaskan bahwa proses internalisasi perintah verbal merupakan langkah yang penting bagi individu dalam menciptakan kendali secara sadar terhadap perilakunya yang diharapkan memunculkan sikap positif terutama kepercayaan diri (overt-covert).

\section{KESIMPULAN DAN SARAN}

Penggunaan self instruction sebagai teknik alternatif mampu meningkatkan kepercayaan diri (overt-covert) siswa SMP, dimana dalam ancangan ini pikiran siswa dikonstruksikan ke arah positif sehingga menimbulkan rasa percaya dirinya. Inti dari teknik ini adalah merestrukturasi sistem kognisi siswa, namun terpusat pada perubahan pola verbalisasi overt dan covert. Teknik self instruction memiliki dua kegunaan, pertama untuk mengganti pemikiran negatif terhadap diri sendiri menjadi pemikiran yang positif dan yang kedua adalah untuk mengarahkan perilaku positif yang salah satunya adalah kepercayaan diri. Inti dari teknik self instruction adalah mengajarkan pada diri sendiri bagaimana mengontrol segala perilaku dan pemikiran-pemikiran negatif yang dapat menyebabkan kurangnya rasa percaya diri siswa. Diharapkan dengan pemberian bantuan menggunakan teknik self instruction ini dapat membantu meningkatkan kepercayaan diri (overt-covert) pada siswa 
tersebut.

Pentingnya kepercayaan diri pada remaja karena merupakan salah satu life skill yang perlu dimiliki. Kepercayaan diri merupakan hal yang membuat anak dapat menyalurkan segala sesuatu yang diketahui dan dikerjakan. Kepercayaan diri juga merupakan sikap positif seorang individu yang memampukan dirinya untuk mengembangkan penilaian positif terhadap diri sendiri maupun terhadap lingkungan.

Saran bagi peneliti yang ingin mengembangkan aplikasi teknik self instruction selanjutnya dapat menambahkan kelompok kontrol dalam pelaksanaan kegiatan penelitian sehingga perbedaan peningkatan kepercayaan diri siswa bisa dilihat antara kelompok yang diberikan treatment dan yang tidak. Selain itu, posttest yang digunakan untuk mengukur peningkatan kepercayaan diri siswa SMP bisa diberikan lebih dari satu kali sehingga dapat dilihat bahwa peningkatkan kepercayaan diri siswa sifatnya tidak hanya sementara setelah diberikan treatment saja dan bisa menggunakan jenis rancangan penelitian lain yaitu time series atau bisa digunakan untuk mengembangkan sikap postif lainnya yang bermanfaat bagi diri siswa.

\section{DAFTAR RUJUKAN}

Afifi, J. 2014. 1 Menit Mengatasi Rasa Percaya Diri. Jogjakarta: CV Flasbook.

Corey, G. 2007. Teori dan Praktek Konseling dan Psikoterapi. Bandung: Rafika Aditama.

Cormier, L.J. \& Cormier, L.S. 2009. Interviewing Strategies for Helpers. 7 ed. Montery, California: Brooks/Code Publishing Company.

Creswell, J.W. 2012. Research Design: Pendekatan Kualitatif, Kuantitatif dan Mixed. Yogyakarta: Pustaka Pelajar.

De Angelish, B. 2005. percaya diri (Sumber Sukses Dan Kemandirian). Jakarta: Gramedia Pustaka Umum.

Fatimah, E. 2006. Psikologi Perkembangan: Perkembangan Peserta Didik. Bandung: Pustaka Setia.

Friedenberg, L. 1995. Psychological Testing, Design, Analysis and Use. Bacon.

Gael, L. 1997. Mendidik Anak Agar Percaya Diri. Jakarta: Arcan.

Hurlock, E. 2006. Psikologi Perkembangan. Jakarta: Penerbit Erlangga

Khusumawati, E. 2014. Penerapan Kombinasi Antara Teknik Relaksasi Dan Self-Intruction Untuk Mengurangi Kejenuhan Belajar Siswa Kelas XII Ipa 2 SMA 22 Surabaya, Jurnal UNESA (online) (http://ejournal.unesa.ac.id/13033//article.pdf, diakses tanggal 22 Oktober 2019).

Meichenbaum, D. \& Biemiller, A. 2008. Nurturing Independent Learners. United States: Cambridge Mass.

Prasetya. 2014. Membangun rasa percaya diri anda. Jogjakarta: CV Flasbook.

Purnama , A. 2012. efektivitas teknik self instruction untuk mereduksi kecemasan menghadapi ujian. Tesis Tidak Diterbitkan: Universitas Pendidikan Indonesia (Online) (http://lib.ui.ac.id/19305/1/1301408016.pdf, diakses tanggal 24 November 2019).

Ormrod, J.E. 1995. Educational Psychology Principles and Aplications. New Jersey, Prentice Hall. 
Slavin, R. E. 1997. Educational Psychology-Theory and Practice. Fourth Edition. Boston: Allyn and Bacon.

Sugiyono. 2015. Metode Penelitian Pendidikan (Penelitian Kuantitatif, Kualitatif, dan R\&D). Bandung: CV. Alfabeta.

Supriyo. 2008. Studi Kasus bimbingan konseling. Semarang: CV Nieuw Setapak.

Vygotsky. 2003. Educational Theory in Cultural Context. Cambridge Universty press.

Winkel,W.S.2006. Bimbingan dan Konseling di Institusi Pendidikan, Edisi Revisi. Yogyakarta: Media Abadi. 